\title{
Пеленочный дерматит:
}

ОТВЕТЫ НА ВОПРОСЫ ПЕДИАТРОВ И РОДИТЕЛЕЙ В СВЕТЕ СОВРЕМЕННЫХ МИРОВЫХ ТЕНДЕНЦИЙ

\section{Е.Н. САВЕРСКАЯ}

Федеральное государственное бюджетное образовательное учреждение высшего образования «Московский государственный университет пищевых производств», Медицинский институт непрерывного образования: 125080, Россия, г. Москва, Волоколамское ш., д. 11

\section{Информация об авторе:}

Саверская Елена Николаевна - д.м.н., врач-дерматовенеролог, клинический фармаколог, профессор кафедры фармации Медицинского института непрерывного образования, Федеральное государственное бюджетное образовательное учреждение высшего образования «Московский государственный университет пищевых производств»; тел.: +7(915) 335-35-86;

e-mail: l.saverskaya@mail.ru

\section{PE310ME}

В обзорной статье приводятся современные данные по вопросам терминологии, распространенности, этиопатогенеза, клиники и дифференциальной диагностики дерматита подгузников (ДП). Особое внимание уделено подходам к предупреждению и лечению ДП. Современные смягчающие и увлажняющие средства, технологии производства и возможности суперпоглощающих подгузников позволили значительно облегчить уход за кожей у новорожденных и младенцев, уменьшить частоту и тяжесть клинических проявлений данного заболевания. Повышение осведомленности родителей и обучение их навыкам ухода за кожей ребенка являются залогом успешной профилактики ДП.

Ключевые слова: дерматит подгузника, пеленочный дерматит, кожа младенцев, уход

Для цитирования: Саверская Е.Н. Пеленочный дерматит: ответы на вопросы педиатров и родителей в свете современных мировых тенденций. Медицинский совет. 2019; 11: 127-134. DOI: https://doi.org/10.21518/2079-701X-2019-11-127-134.

Конфликт интересов: автор заявляет об отсутствии конфликта интересов.

\section{Diaper Dermatitis:}

\section{ANSWERS TO QUESTIONS MOST FREQUENTLY ASKED BY PEDIATRICIANS AND PARENTS IN THE LIGHT OF RECENT GLOBAL TRENDS}

\section{Elena N. SAVERSKAYA}

Federal State Budgetary Institution of Higher Education «Moscow State University of Food Production», Medical Institute of Continuing Education: 125080, Russia, Moscow, Volokolamskoe shosse, 11

\section{Author credentials:}

Saverskaya Elena Nikolaevna - Dr. of Sci. (Med.), Dermatovenerologist, Clinical Pharmacologist, Professor of Chair for Pharmacy, Medical Institute of Continuing Education, Federal State Budgetary Institution of Higher Education «Moscow State University of Food Production»; tel.: +7(915) 335-35-86; e-mail: l.saverskaya@mail.ru

\section{ABSTRACT}

The review provides current data on terminology, prevalence, etiopathogenesis, clinic and differential diagnosis of diaper dermatitis (DD). Particular attention is paid to approaches to the prevention and treatment of DD. Modern emollients and moisturisers, production technologies and possibilities of superabsorbing diapers have made it possible to significantly facilitate skin care for newborns and infants, and reduce the frequency and severity of the clinical manifestations of this disease. The key to successful prevention of DD is raising parents' awareness and teaching them how to care for their baby's skin.

Keywords: diaper dermatitis, $W$-dermatitis, babies' skin, care

For citing: Saverskaya E.N. Diaper Dermatitis: answers to questions most frequently asked by pediatricians and parents in the light of recent global trends. Meditsinsky Sovet. 2019; 11: 127-134. DOI: https://doi.org/10.21518/2079-701X-2019-11-127-134.

Conflict of interest: The author declare no conflict of interest. 


\section{ВВЕДЕНИЕ}

Несмотря на то что современная индустрия располагает достаточным количеством средств, значительно облегчивших уход за детьми самого раннего возраста, проблема пеленочного дерматита остается довольно острой. Это беспокоит педиатров, которые сталкиваются, как правило, с более сложными клиническими проявлениями на коже у малышей в области подгузников, а также родителей, которые в первые два года жизни ребенка неоднократно могут наблюдать высыпания от самых легких до более интенсивных.

Довольно часто в настоящее время родители получают знания по данной проблеме из социальных сетей, подписываясь на личные блоги докторов или обсуждая эту тему на различных форумах между собой. С одной стороны, доступность информации в сети интернет помогает мамам развеять определенные сомнения и найти хорошие средства по уходу за кожей малышей, с другой стороны, зачастую родители могут неверно расценить высыпания на коже у ребенка, начать самолечение и тем самым способствовать более длительному и тяжелому течению дерматита.

В данном обзоре мы постараемся ответить на вопросы педиатров и родителей, обобщив все самые актуальные мировые тенденции в области диагностики, профилактики и лечения пеленочного дерматита.

\section{ВОПРОСЫ СОВРЕМЕННОЙ ТЕРМИНОЛОГИИ}

Что же такое «пеленочный дерматит», или «дерматит подгузника»? У англоязычного термина «diaper» имеется несколько вариантов перевода на русский язык - памперсы, подгузники, пеленки, ткань. Если учесть факт, что непосредственно в тканевой пеленке в настоящее время младенцы находятся довольно ограниченное время, а в подгузнике (одноразовом или тканевом) практически от рождения и до момента формирования навыка пользоваться горшком и носить трусы, то наиболее верным, на наш взгляд, является употребление термина «дерматит подгузника» (ДП), именно этой терминологии мы и будем придерживаться в данной статье. ДП представляет собой воспалительную реакцию кожи, локализованную в области ношения подгузника и обусловленную раздражающим воздействием мочи и стула в условиях окклюзии, создаваемой подгузником [24]. В этой области у младенцев и детей раннего возраста могут иметь место проявления различных локальных или генерализованных дерматозов, а также системных заболеваний [19, 32]. Здесь важно обратить внимание на то, что сам термин является скорее описательным, не отражает этиопатогенеза заболевания, связан с локализацией процесса, раздражающими факторами и не должен приравниваться автоматически к реакции на сам подгузник $[44,48]$.

\section{Как часто родители и врачи сталкиваются с этой проблемой?}

Истинная частота заболеваемости и распространенности ДП во всем мире, в том числе и в нашей стране, неизвестна, а имеющиеся данные сильно различаются, поскольку большая часть случаев остается не зафиксированной официальной статистикой [1, 32]. Тем не менее в зарубежных публикациях последних лет фигурируют цифры от 16 до 70\%, наиболее часто - 50-65\%, фактически каждый второй младенец (независимо от пола) имеет ДП той или иной степени тяжести в то или иное время $[1,35]$. При этом только 7\% родителей, дети которых имеют сыпь в области подгузника, обращаются к врачам первичного звена [11].

По данным исследований, при рождении у детей клинические проявления ДП, как правило, отсутствуют, но уже к четвертой неделе жизни они могут отмечаться у 25\% новорожденных [49]. Пики частоты встречаемости ДП приходятся на возраст от 9 до 12 месяцев и далее на второй год жизни ребенка [1]. При этом 58\% детей имеют незначительную сыпь, 34\% - умеренную, 8\% ярко выраженную $[4,26]$.

\section{Влияют ли особенности кожи малышей на развитие дП?}

Как известно, созревание кожного покрова у плода происходит по мере увеличения срока гестации, и к моменту рождения он вполне сформирован и функционирует. В коже здорового новорожденного ребенка имеется достаточно выраженный эпидермис, хорошо сформированные слои рогового слоя, а трансдермальная потеря воды очень низкая. При рождении $\mathrm{pH}$ кожи более щелочной и составляет 7,08, но уже в течение первой недели жизни быстро снижается, начинает формироваться кислотная мантия и к четвертой неделе $\mathrm{pH}$ приближается к показателям взрослого - от 5,0 до 5,5 [25, 29].

Дерма у младенцев менее развита и более тонкая, коллагеновые волокна в ней короче и менее плотные, эпидермо-дермальные контакты недостаточно плотные. Когда-то существовало мнение, что здоровые новорожденные имеют сформированный кожный барьер, идентичный взрослым [31], однако исследования последних лет показали, что полное созревание рогового слоя может продолжаться до года [39]. Тем не менее кожа здоровых новорожденных, имеющая практически полноценный функционирующий роговой слой и кислотную мантию, помогает защитить от раздражителей и микробных агентов, вызывающих дерматит в области подгузников.

У недоношенных детей, особенно с очень низким весом при рождении и с меньшим сроком гестации, роговой слой не развит, повышена трансдермальная потеря воды и имеется дефицит дермальных белков. Это способствует повышенному риску повреждений кожи и проницаемости ее для различных экзогенных агентов и инфекции $[36,50]$.

В исследованиях было показано, что полное формирование барьерной функции у недоношенных детей, родившихся на сроке гестации 30-32 недели, происходит от 2 до 4 недель после рождения, однако при рождении на сроках 25 недель и менее этот период может занять 8-9 недель после родов, поэтому недоношенные дети наиболее чувствительны к развитию ДП [31]. 


\section{Какие факторы предрасполагают к развитию дп?}

Ведущим этиологическим фактором ДП является повышенная влажность кожи в условиях окклюзии, создаваемой подгузником. Имеется корреляция между тяжестью клинических проявлений ДП и влажностью кожи. При трении в области подгузника развивается мацерация рогового слоя эпидермиса, что приводит к нарушению физиологического защитного барьера кожи [8].

Раздражающим действием на кожу обладают моча и фекальные пищеварительные ферменты, особенно протеазы и липазы, которые, с одной стороны, увеличивают проницаемость кожи для солей желчи и других потенциальных раздражителей, с другой стороны, сами соли желчи потенцируют раздражающую активность фекальных ферментов. Фекальные уреазы катализируют процесс расщепления мочевины до аммиака, который изменяет $\mathrm{pH}$ кожи в щелочную сторону, что ведет к более высокой активности фекальных ферментов [3, 8, 16, 50].

Кроме того, сама частота стула, и особенно диарея, могут усугублять развитие ДП вследствие того, что в фекалиях содержатся высокие концентрации остаточных пищеварительных ферментов, имеющих более короткое время пребывания в кишечнике $[1,2,26]$.

Зарубежные авторы отмечают, что грудное вскармливание способствует предотвращению развития ДП, поскольку фекалии младенцев, его получающих, обладают более низким $\mathrm{pH}$, меньшей активностью пищеварительных протеаз и липаз, а также низким содержанием уреаз по сравнению с детьми, получающими искусственное вскармливание [8].

Микроорганизмы фекалий, особенно Candida albicans и Staphylococcus aureus, попадая на поврежденную кожу, могут приводить к развитию более тяжелых случаев ДП, осложненных вторичной инфекцией $[17,22]$.

Таким образом, сочетанное влияние как физиологических, так и биохимических факторов приводит к появлению высыпаний в области подгузника у детей (рис. 1).

Рисунок 1. Этиопатогенез дерматита подгузника

Figure 1. Etiopathogenesis of diaper dermatitis

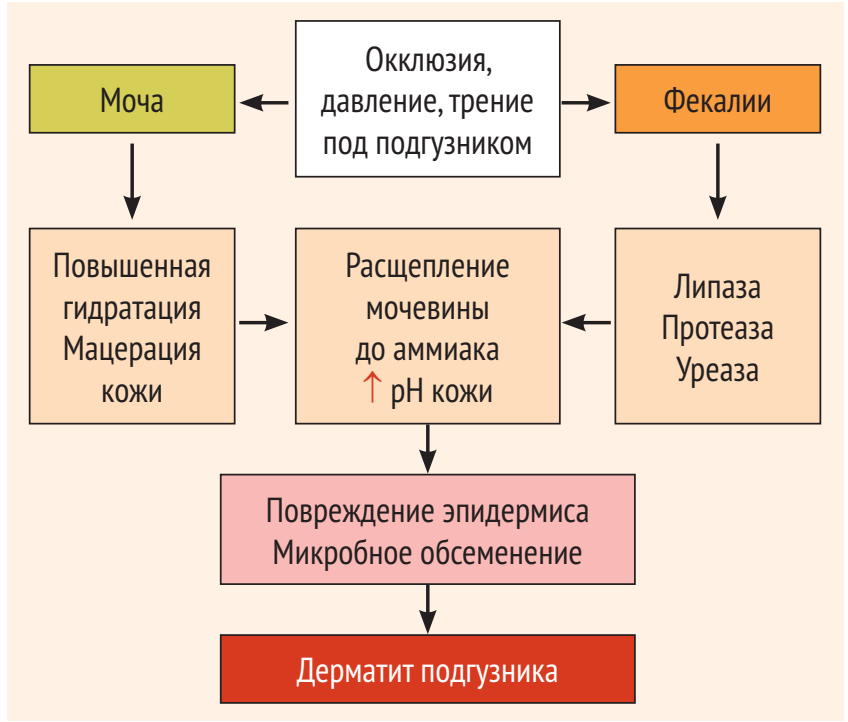

\section{Какие клинические проявления соответствуют дерматиту подгузника?}

Высыпания при ДП локализуются на выступающих участках, соприкасающихся с подгузником, где повышено трение кожи, - внутренняя поверхность бедер, ягодицы, перианальная область, гениталии, живот и область талии. На самых ранних этапах развития сыпь представлена легкой эритемой, занимающей небольшую область. По мере прогрессирования процесса увеличиваются как площадь, так и интенсивность гиперемии, могут появляться папулы, пустулы, эрозии. Для оценки степени тяжести ДП Brown W.M. et al. (2006) предложили специальную шкалу, в которой клинические проявления соответствуют баллам от 0 до 3 (табл. 1).

При осложнении ДП вторичной инфекцией, наиболее часто - кандидозом, в процесс вовлекаются кожные складки, интенсивность эритемы более выражена, на коже появляются эритематозные бляшки и папулы.

Высыпания на коже сопровождаются болезненными ощущениями и являются стрессом для ребенка; родители отмечают, что он становится более беспокойным, часто плачет. Наряду с этим, внешне страдает мимика малыша его глазки сжаты, углубляются носогубные складки. Могут наблюдаться изменения пищевых привычек, нарушения сна, уменьшение частоты мочеиспусканий и дефекации [27]. В качестве молекулярного индикатора стресса у детей с ДП в исследованиях было показано изменение уровне кортизола слюны [45]. Родители и педиатры должны обращать внимание не только на появление высыпаний на коже у ребенка, но и на изменение его поведения, что может быть самым ранним симптомом начинающегося ДП.

Продолжительность неосложненного ДП составляет, как правило, около трех дней, и при своевременном и правильном уходе клинические проявления быстро регрессируют, при присоединении вторичной инфекции и при тяжелом течении длительность заболевания может варьировать [38, 46].

\section{Что может помочь врачу в постановке верного диагноза ДП?}

Как мы уже обсуждали выше, у детей раннего возраста в области подгузников высыпания могут иметь место не только при ДП, но и при других заболеваниях, с которыми врачу приходится проводить дифференциальную диагностику. Для этого необходимо оценить не только общее состояние и внешний вид кожных покровов, но и правильно собрать анамнез.

Fölster-Holst R. et al. (2011) рекомендуют задавать врачу ряд вопросов, ответ на которые поможет поставить точный диагноз ДП [23]:

1. Как долго имеются высыпания на коже в области подгузника? Средний возраст начала ДП, как правило, соответствует 9-12 месяцам жизни ребенка. Если высыпания на коже имеются до или после этого периода, возможны и другие причины воспаления.

2. В каких областях локализуется дерматит? Высыпания в области выступающих участков, контактирующих с подгузником (в том числе внутренняя поверхность бедер, половые губы, мошонка, нижняя часть живота), относятся к стандартным проявлениям ДП. 
Таблица 1. Клиническая шкала оценки степени тяжести дерматита подгузника [18]

Table 1. A clinical scale for assessing the severity of diaper dermatitis [18]

\begin{tabular}{|c|c|c|}
\hline Баллы & Степень тяжести & Определение \\
\hline 0 & Отсутствует & Кожа чистая (может быть небольшая сухость и/или единичные папулы, но не эритема) \\
\hline 0,5 & Легкая & $\begin{array}{l}\text { Незначительное покраснение на очень небольшой площади (< 2\%), также могут встречаться единичные папулы } \\
\text { и/или легкая сухость }\end{array}$ \\
\hline 1,0 & Умеренно легкая & $\begin{array}{l}\text { Слабое покраснение на небольшом участке (2-10\%), или выраженное покраснение на небольшой площади (<2\%), } \\
\text { и/или рассеянные папулы, и/или небольшая сухость }\end{array}$ \\
\hline 1,5 & Умеренная & $\begin{array}{l}\text { Слабое покраснение на большей площади (10\%), или выраженное покраснение на небольшой площади (2-10\%), } \\
\text { или очень интенсивное покраснение на небольшой площади (<2\%), и/или рассеянные папулы (<10\% площади), } \\
\text { и/или умеренная сухость }\end{array}$ \\
\hline 2,0 & Средняя & $\begin{array}{l}\text { Выраженное покраснение на большей площади }(10-50 \%), \text { или очень интенсивное покраснение на небольшой } \\
\text { площади (<2\%), и/или от одной до нескольких областей папул }(10-50 \%) \text { с } 5 \text { или меньшим числом гнойничков, может } \\
\text { отмечаться небольшое шелушение или отек }\end{array}$ \\
\hline 2,5 & Умеренно тяжелая & $\begin{array}{l}\text { Выраженное покраснение на большой площади (>50\%), или очень интенсивное покраснение на небольшой площади } \\
(2-10 \%) \text { без отека, и/или большие площади (>50\%) с несколькими папулами и/или пустулами; может иметь место } \\
\text { умеренное шелушение и/или отек }\end{array}$ \\
\hline 3,0 & Тяжелая & $\begin{array}{l}\text { Очень интенсивная краснота на большой площади (>10\%), и/или сильное шелушение, сильный отек, эрозии и язвы; } \\
\text { могут встречаться большие площади сливающихся папул или многочисленных гнойничков/пузырьков }\end{array}$ \\
\hline
\end{tabular}

3. Имеются ли у младенца стигмы других заболеваний кожи, таких как атопический дерматит, псориаз, себорейная экзема? Существует ли семейный анамнез этих заболеваний?

4. Как родители/опекуны проводят очистку кожи младенца? Используют ли они мыло или детские салфетки? Как часто купают ребенка?

5. Какие подгузники (одноразовые или тканевые) и какие смягчающие кремы используются в уходе за ребенком? Имеются ли вещества, способные вызвать аллергический контактный дерматит, в составе подгузников (полимеры, красители) или смягчающих кремов (ароматизаторы, консерванты)?

6. Существует ли взаимосвязь высыпаний на коже с отлучением или введением новых пищевых продуктов?

7. Имеются ли у младенца гастроэнтерит или другие заболевания кишечника, вызывающие диарею?

8. Принимает ли ребенок антибактериальные или другие лекарственные препараты, вызывающие диарею?

9. Сопровождаются ли высыпания на коже болью и зудом? В таблище 2 приводятся заболевания, с которыми необходимо дифференцировать ДП, а также особенности анамнеза, морфологии и локализации сыпи и изменений общего состояния ребенка (Fölster-Holst R., 2018).

Своевременно поставленный диагноз позволит врачу назначить необходимое лечение, а также порекомендовать родителям предпочтительные средства ухода за кожей ребенка, чтобы избежать повторения эпизодов ДП.

\section{Как предотвратить ДП?}

Поскольку ДП - многофакторная проблема и основными задачами по его управлению являются ускорение заживления поврежденной кожи и предотвращение появления новых эпизодов, внимание врача-педиатра и родителей должно быть сфокусировано прежде всего на устранении причинно-следственных факторов [13].
Цели ухода за кожей ребенка в профилактике ДП [4,11]: - Поддержание функций барьера кожи.

- Обеспечение сухости кожи.

- Уменьшение трения кожи в области ношения подгузника.

- Ограничение воздействия раздражителей.

Современные средства ухода за кожей малышей, достижения в области технологий производства подгузников (модернизация дизайна, состава и возможностей использования), а также клинические исследования влияния ухода за кожей позволили существенно снизить частоту и тяжесть ДП [7, 13, 40, 48].

Обновленные рекомендации Европейского круглого стола 2016 г. (Blume-Peytavi U., Lavender T., Jenerowicz D. et al., 2016), в разработке которых принимали участие в том числе и эксперты из России, были посвящены лучшим методам ухода за кожей младенцев, включая профилактику ДП (табл. 3).

\section{Купание и очищение кожи}

Купание для младенцев наиболее предпочтительно по сравнению с обычным протиранием кожи. Имеются клинические данные, подтверждающие эффективность смягчающих очищающих средств для купания новорожденных и младенцев в профилактике ДП и улучшении барьерных функций кожи [47]. Как отмечено в рекомендациях круглого стола, состав идеальных для младенцев жидких очищающих и смягчающих средств (эмолентов) должен иметь либо нейтральный, либо подкисленный $\mathrm{pH}$ и содержать только безопасные ингредиенты, одобренные регуляторными службами Европейского медицинского агентства (European Medicines Agency) или Управления по контролю за продуктами и лекарствами США (Food and Drug Administration) [12]. В современной практике педиатры используют средства по уходу за кожей, имеющие физиологический $\mathrm{pH}$ и не содержащие парабены, например Первую очищающую воду (Урьяж), способствующую мягкому 
удалению любых загрязнений с поверхности кожи лица, тела и области под подгузником. Термальная вода и входящий в ее состав экстракт алоэ вера оказывает увлажняющее, успокаивающее и укрепляющее барьерные свойства кожи действие. При нанесении на кожу не требует смывания водой. Кроме этого средства, стоит обратить внимание на Первый очищающий пенящийся крем - мягкое очищающее средство для кожи ребенка без мыла на основе
Термальной воды Урьяж с добавлением масла иллипа, богатое Омега-3/Омега-6 полиненасыщенными жирными кислотами (ПНЖК), что способствует насыщению кожи аминокислотами, ее смягчению и укреплению гидролипидных свойств. Первое очищающее пенящееся масло Урьяж также обладает свойством мягкого очищения кожи без мыла, при этом, не нарушая целостности гидролипидной пленки, смягчая и увлажняя кожу ребенка.

Таблица 2. Дифференциальная диагностика дерматита подгузника [24]

Table 2. Differential diagnosis of diaper dermatitis [24]

\begin{tabular}{|c|c|c|c|c|c|}
\hline Заболевание & Причина & Морфология сыпи/локализация & Общее состояние & Анамнез пациента & Семейный анамнез \\
\hline \multicolumn{6}{|c|}{ Экзематозные заболевания и псориаз } \\
\hline $\begin{array}{l}\text { Ирритативный контакт- } \\
\text { ный дерматит }\end{array}$ & $\begin{array}{l}\text { Трение подгузника, } \\
\text { контакт с раздражите- } \\
\text { лями (стул, моча) }\end{array}$ & $\begin{array}{l}\text { Эритема, папулы, шелушение/ } \\
\text { выступающие поверхности }\end{array}$ & Хорошее & Неспецифичен & Неспецифичен \\
\hline $\begin{array}{l}\text { Аллергический контакт- } \\
\text { ный дерматит }\end{array}$ & $\begin{array}{l}\text { Аллергия на вещества } \\
\text { подгузника и/или смяг- } \\
\text { чающие средства }\end{array}$ & $\begin{array}{l}\text { Эритема, везикулы, чешуйки/ } \\
\text { выступающие поверхности, } \\
\text { области контакта }\end{array}$ & Хорошее & Неспецифичен & Неспецифичен \\
\hline $\begin{array}{l}\text { Младенческая себорей- } \\
\text { ная экзема }\end{array}$ & $\begin{array}{l}\text { Неизвестна, ассоциация } \\
\text { c Malassecia spec. }\end{array}$ & $\begin{array}{l}\text { Желтоватые чешуйки, эритема/ } \\
\text { складки кожи, волосистая часть } \\
\text { головы }\end{array}$ & Хорошее & Неспецифичен & Неспецифичен \\
\hline $\begin{array}{l}\text { Младенческий атопиче- } \\
\text { ский дерматит }\end{array}$ & $\begin{array}{l}\text { Генетическое и эколо- } \\
\text { гическое влияние }\end{array}$ & $\begin{array}{l}\text { Экзематозные высыпания/ } \\
\text { выступающие поверхности, } \\
\text { волосистая часть головы, щеки, } \\
\text { разгибательная поверхность } \\
\text { конечностей }\end{array}$ & $\begin{array}{l}\text { Зуд, связанный с } \\
\text { пищевой аллергией и } \\
\text { младенческой астмой }\end{array}$ & Неспецифичен & $\begin{array}{l}\text { Атопические забо- } \\
\text { левания у родите- } \\
\text { лей или кровных } \\
\text { родственников }\end{array}$ \\
\hline Младенческий псориаз & $\begin{array}{l}\text { Генетическое и эколо- } \\
\text { гическое влияние }\end{array}$ & $\begin{array}{l}\text { Эритематосквамозные бляшки/ } \\
\text { выступающие участки, пупок, } \\
\text { паховые складки }\end{array}$ & Хорошее & Неспецифичен & $\begin{array}{l}\text { Псориаз у членов } \\
\text { семьи }\end{array}$ \\
\hline \multicolumn{6}{|c|}{ Инфекционные заболевания } \\
\hline Чесотка & $\begin{array}{l}\text { Клещи Sarcoptes sca- } \\
\text { bies }\end{array}$ & $\begin{array}{l}\text { Полиморфные высыпания/ } \\
\text { складки кожи, ладонно-подо- } \\
\text { швенные }\end{array}$ & Зуд & $\begin{array}{l}\text { Контакт с заболевши- } \\
\text { ми лицами }\end{array}$ & $\begin{array}{l}\text { Члены семьи, имею- } \\
\text { щие чесотку }\end{array}$ \\
\hline Кандидозная инфекция & Candida albicans & $\begin{array}{l}\text { Папулы, пустулы/сопутствуют } \\
\text { высыпаниям при ДП }\end{array}$ & - & $\begin{array}{l}\text { Развивается на фоне } \\
\text { ДП }\end{array}$ & Неспецифичен \\
\hline $\begin{array}{l}\text { Перианальный стрепто- } \\
\text { кокковый и стафило- } \\
\text { кокковый дерматит }\end{array}$ & $\begin{array}{l}\text { Стрептококки, стафило- } \\
\text { кокки }\end{array}$ & $\begin{array}{l}\text { Эритема, трещины/перианаль- } \\
\text { ная область }\end{array}$ & $\begin{array}{l}\text { Зуд, жжение, боль, } \\
\text { преимущественно } \\
\text { после дефекации }\end{array}$ & $\begin{array}{l}\text { Тонзиллит в некото- } \\
\text { рых случаях }\end{array}$ & $\begin{array}{l}\text { Тонзиллит у членов } \\
\text { семьи }\end{array}$ \\
\hline \multicolumn{6}{|c|}{ Алиментарные заболевания } \\
\hline $\begin{array}{l}\text { Энтеропатический } \\
\text { акродерматит }\end{array}$ & Мутация гена SLE 39A4 & $\begin{array}{l}\text { Экссудативные псориазиформ- } \\
\text { ные высыпания/перианальная } \\
\text { область, дистальная часть } \\
\text { конечностей }\end{array}$ & Диарея, алопеция & $\begin{array}{l}\text { 2-3 недели после } \\
\text { отлучения от груди }\end{array}$ & - \\
\hline \multicolumn{6}{|c|}{ Аутоиммунные и заболевания неизвестной этиологии } \\
\hline Склеродермия & Неизвестна & $\begin{array}{l}\text { Эритема, атрофия/перианаль- } \\
\text { ная область, вульва }\end{array}$ & Боль, зуд, дизурия & Неспецифичен & Неспецифичен \\
\hline Болезнь Кавасаки & Неизвестна & $\begin{array}{l}\text { Эритема, отечность/область } \\
\text { подгузника, руки, ноги, губы }\end{array}$ & $\begin{array}{l}\text { Коронарная } \\
\text { аневризма }\end{array}$ & $\begin{array}{l}\text { Лихорадка, } \\
\text { отсутствие ответа на } \\
\text { антибиотикотерапию, } \\
\text { лимфоаденопатия }\end{array}$ & - \\
\hline \multicolumn{6}{|c|}{ Неоплазии } \\
\hline $\begin{array}{l}\text { Гистиоцитоз клеток } \\
\text { Лангерганса }\end{array}$ & Неизвестна & $\begin{array}{l}\text { Импетигоподобные высыпания } \\
\text { в складках кожи, экссудативные } \\
\text { папулы в перианальной обла- } \\
\text { сти, высыпания по типу себо- } \\
\text { рейного дерматита в заушных } \\
\text { складках }\end{array}$ & $\begin{array}{l}\text { Связано с вовлечени- } \\
\text { ем других органов } \\
\text { (главным образом } \\
\text { костей, легких, } \\
\text { печени) }\end{array}$ & - & - \\
\hline
\end{tabular}


Таблица 3. Новые рекомендации Европейского круглого стола по уходу за кожей младенцев в области подгузников [12] Table 3. New recommendations from a European Roundtable meeting on the infant skin care in the area ofdiapers [12]

\begin{tabular}{|c|c|c|}
\hline Новые рекомендации & $\begin{array}{c}\text { Уровень } \\
\text { доказательности }\end{array}$ & $\begin{array}{c}\text { Уровень } \\
\text { рекомендаций }\end{array}$ \\
\hline Область подгузника должна быть чистой и сухой & Высокий & Высокий \\
\hline Подгузники следует менять так часто, насколько это необходимо, чтобы обеспечить чистоту и сухость кожи & Средней силы & Высокий \\
\hline $\begin{array}{l}\text { Кожу области подгузника следует осторожно очищать ватными шариками/дисками или мягкой салфеткой и } \\
\text { только водой или с использованием специально разработанных салфеток }\end{array}$ & Средней силы & Высокий \\
\hline Специально разработанные салфетки можно использовать с рождения* & Средней силы & Высокий \\
\hline Салфетки можно использовать при каждой смене подгузника & Средней силы & Слабый \\
\hline $\begin{array}{l}\text { Высыхание кожи может быть достигнуто путем естественного высыхания на воздухе или нежного } \\
\text { промокания сухим полотенцем или сухими ватными шариками/дисками }\end{array}$ & Средней силы & Высокий \\
\hline Область подгузника перед купанием должна быть очищена, если это необходимо & Средней силы & Высокий \\
\hline
\end{tabular}

*Салфетки должны содержать рН-буфер для поддержания небольшой кислотности кожи и должны быть свободны от потенциальных раздражителей, таких как спирты, ароматические добавки, эфирные масла, мыло и агрессивные синтетические моющие средства (например, лаурилсульфат натрия); они должны содержать хорошо переносимые консерванты.

\section{Влажные салфетки}

Имеющиеся данные свидетельствуют о том, что детские салфетки не вредят и не нарушают физиологического созревания кожного барьера у младенцев [11]. Рецептура современных салфеток предусматривает использование pH-буферов, которые противодействуют щелочной реакции мочи и поддерживают кислотность кожи в области подгузника. Кроме того, очень важно, чтобы салфетки не содержали потенциальных раздражителей, поскольку имеются случаи аллергического контактного дерматита у детей на консерванты, входящие в состав некоторых салфеток, такие как methylisothiazolinone (MI), methylchloroisothiazolinone (MCl), bronopol (2-bromo-2-nitropropane-1,3-diol), iodopropynyl butylcarbamate. Поскольку влажные салфетки могут быть хорошей средой для роста микроорганизмов, они должны содержать подходящие и безопасные консерванты $[2,4,12,34]$. Например, Первые очищающие салфетки Урьяж, изготовленные из 100\%-ного хлопка, за счет входящих в состав Термальной воды Урьяж и экстракта алоэ вера мягко удаляют любые загрязнения с поверхности кожи лица, тела и зоны под подгузником, а также увлажняют, успокаивают и укрепляют барьерные свойства кожи. При этом имеют физиологический рН и не содержат парабенов. После их применения не требуется смывания водой. Выпускаются салфетки в удобной упаковке с клапаном.

\section{Использование эмолентов и других средств по уходу}

В настоящее время в развитых странах эмоленты (смягчающие средства) применяют в качестве первой линии для профилактики и лечения ДП [4, 32]. Эмоленты содержат липиды, которые защищают кожу в области подгузника, проникая в межклеточные пространства рогового слоя, предотвращая воздействие чрезмерной влажности и раздражителей, способствуя восстановлению эпидермиса $[4,46]$. Однако они могут использоваться для поддержания барьерной функции кожи при условии, что наносятся тонким слоем в области подгузника, избегая окклюзии, особенно в складках кожи, чтобы не вызвать нарушений естественного испарения и предотвратить колонизацию патогенной микробной флорой. У младенцев со здоровой кожей эмоленты применяют по крайней мере два раза в неделю [12]. Среди смягчающих средств имеется большое разнообразие составов, содержащих оксид цинка, вазелиновое масло, рыбий жир, диметикон, ланолин, декспантенол, раствор Бурова, смесь ацетата алюминия в воде [28, 32 , 47]. Стоит обратить внимание на средства превентивной меры, например на Термальную воду Урьяж. Это природная изотоническая вода с наиболее сбалансированным содержанием минеральных солей и олигоэлементов, физиологическим рН, без ароматизаторов. Термальная вода стимулирует выработку двух основных протеинов кожи - филаггрина и клоудина, способствует укреплению кожного и иммунного барьера, уменьшает ТЭПВ. Успокаивает и защищает кожу, уменьшает раздражение и зуд, надолго увлажняет, подходит для обработки кожи лица, тела и области под подгузником, включая слизистые оболочки. Легко наносится методом распыления, после чего не требует промакивания. На основе Термальной воды изготовлен и Первый защитный крем под подгузник Урьяж - средство профилактики ДП. В креме нет ароматизаторов, а, кроме Термальной воды, в состав включены скваланы, стеролы и запатентованный комплекс Poly-2P. Благодаря этим компонентам крем оказывает защитное и изолирующее действие без окклюзии, способствует укреплению барьерных свойств кожи. Включение смягчающих средств в состав верхнего слоя современных подгузников позволяет уменьшить частоту появления эритемы в области их ношения [43].

\section{Технология подгузников}

За последние десятилетия значительно улучшилась технология и дизайн подгузников, что привело к снижению распространенности и тяжести ДП [41, 42, 48]. Самый верхний слой (на внутренней стороне подгузника) является основным материалом, который контактирует с кожей младенца. Анатомические подгузники премиум-класса содержат в этом слое эмолент, действующий против влаги и раздражителей, а также как средство для кондиционирования кожи. Внутренний слой («сердечник») подгузника состоит из суперпоглощающих полимеров (СПП), которые могут впитывать жидкости в 30 раз более собственного 
веса [43]. Более 450 исследований безопасности данной технологии изготовления было проведено, чтобы доказать отсутствие раздражения кожи, сенсибилизации и других рисков при ношении таких подгузников [4, 20]. Суперпоглощающие полимеры, например структурированный полиакрилат натрия, в сухом виде выглядят как мелкие прозрачные кристаллы, при контакте с жидкостью они набухают и превращаются в гелеобразное вещество [48]. Несмотря на высокую поглощающую способность, СПП не являются водорастворимыми и не будут полностью разрушаться при влажном состоянии. В виде геля СПП особенно долговечны и могут выдерживать высокое давление, избегая повторного увлажнения даже при активном поведении детей [21, 33]. Технология образования геля при контакте с мочой в подгузнике помогает нормализовать $\mathrm{pH}$ кожи и приводит к уменьшению ее чрезмерной гидратации и трения. В ретроспективной оценке многочисленных клинических испытаний частота умеренного и тяжелого ДП снижалась на 50\% после введения в технологию производства подгузников СПП [42]. Внешний воздухопроницаемый слой подгузника состоит из микропористых мембран, которые позволяют пропускать поток испарений, но не капли воды, уменьшая тем самым гипергидратацию и окклюзию кожи [15, 42]. Материалы с повышенной эластичностью используются для более удобной посадки и уменьшения трения кожи в области ношения подгузника [5, 6, 48]. В недавнем исследовании было показано, что китайские младенцы в современных подгузниках испытывали меньше нарушений сна по сравнению с носящими тканевые подгузники [48].

\section{Что предпочтительнее для лечения тяжелых и осложнен- ных ДП?}

Для лечения осложненных форм ДП при раздражении с мокнутием в области подгузника применяют антибактериальные и противовоспалительные средства. Например, Cnрей с CU-ZN+ против раздражений без ароматизаторов на основе Термальной воды Урьяж с добавлением глюконатов меди, цинка, смектита и запатентованного комплекca TLR2-Regul. Спрей оказывает антибактериальное, раннее противовоспалительное, успокаивающее и абсорбирующее действие, кроме этого, усиливает естественные защитные свойства кожи. Преимущество этого средства заключается в бесконтактном нанесении, что значительно облегчает использование средства и уменьшает вероятность присоединения вторичной инфекции.

Лечение более тяжелых форм ДП, особенно осложненных вторичной инфекцией, требует медикаментозной терапии, с учетом всех провоцирующих факторов и распространенности процесса на коже. В это время необходимо избегать применения защитных кремов или лекарственных препаратов, обладающих раздражающим или аллергическим компонентами, таких как борная кислота, камфора, фенол, бензокаин, салицилаты и др. [30, 44].

Топические глюкокортикостероиды (ТГКС) с низкой и умеренной активностью необходимо назначать с учетом возраста ребенка, тяжести ДП и в ограниченный период времени (как правило, не более одной недели), чтобы умень- шить воспаление и раздражение кожи. При правильном их использовании удается быстро, эффективно и без побочных эффектов купировать процесс. Следует избегать применения сильных ТГКС, особенно в складках кожи, чтобы избежать побочных явлений в виде атрофии, стрий и тахифилаксии. Родителей необходимо обучить правильному дозированию ТГКС, используя методику единицы FTU (fingertip unit - единица, равная кончику пальца) [9]. После короткого курса ТГКС необходимо регулярно использовать смягчающие средства и сосредоточиться на профилактических мерах, ограничивая воздействие раздражающих агентов [28].

В случае кандидозного инфицирования кожи местные противогрибковые препараты, содержащие нистатин, клотримазол, микозолон, кетоконазол, циклопирокс, можно наносить при каждой смене подгузника [10, 44]. Комбинированные ТГКС, содержащие антимикотик, могут значительно уменьшить воспаление и способствовать более быстрому регрессированию симптомов ДП. При бактериальном обсеменении необходимо применять местные антибактериальные препараты дважды в день на протяжении 5-7 дней. В случае стрептококкового инфицирования может потребоваться курс пероральных антибиотиков [44].

С практической точки зрения все профилактические и лечебные мероприятия в отношении ДП могут быть обобщены в так называемом подходе «ABCDE» (puc. 2) [14, 37]:

Air (воздух) - это простой, безопасный и эффективный способ уменьшить воздействие раздражителей на кожу ребенка. Удаление подгузника позволяет коже высохнуть на воздухе и предотвратить трение.

Barrier (защита) - использование защитных кремов является как профилактической,так и лечебной мерой при ДП. Необходимо наносить такие средства при каждой смене подгузника на все участки кожи, подвергающиеся воздействию раздражающих факторов, мочи и фекалий.

Рисунок 2. «ABCDE»-подход в профилактике и лечении ДП Figure 2. $A B C D E$-approach to the prevention and treatment of $D D$

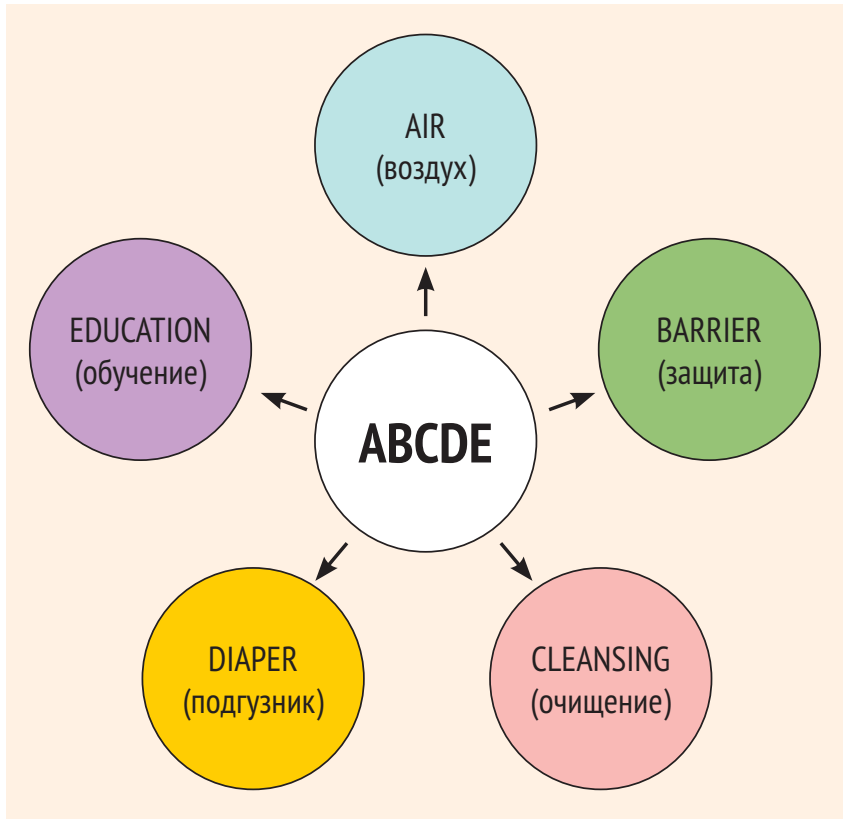


Cleansing (очищение) - необходимо бережное очищение кожи водой и мягкой тканью (салфетками) при каждой смене подгузника, избегая интенсивного протирания кожи.

Diaper (подгузник) - использование современных суперпоглощающих подгузников наиболее предпочтительно по сравнению с тканевыми. Замена подгузника должна производиться по мере его загрязнения, чтобы обеспечить чистоту и сухость кожи ребенка.

Education (обучение) - родители должны получать необходимые знания в области гигиены младенцев от врачей-педиатров и медицинских сестер. Обучение родителей уходу за кожей ребенка является важным фактором как профилактики, так и лечения ДП.

\section{ЗАКЛЮЧЕНИЕ}

Подводя итог всему, что обсуждалось в данной обзорной статье, важно подчеркнуть, что дерматит подгузника представляет собой довольно распространенную многофакторную проблему состояния кожи у младенцев и детей раннего возраста. Современные смягчающие средства, а также технологии производства и возможности суперпоглощающих подгузников позволили значительно облегчить уход за кожей, уменьшить частоту и тяжесть клинических проявлений ДП. Повышение осведомленности родителей и обучение их навыкам ухода за малышом будет способствовать профилактике ДП.

Поступила/Received 20.12.2018

\section{ЛИTEPATYPA/REFERENCES}

1. Adalat S., Wall D., Goodyear H. Diaper dermatitis-frequency and con-tributory factors in hospital attending children. Pediatr Dermatol. 2007;24:483-488.

2. Adam R. Skin care of the diaper area. Pediatr Dermatol. 2008;25:427-433.

3. Andersen P.H., Bucher A.P., Saeed I. et al. Faecal enzymes: in vivo human skin irritation. Contact Dermatitis. 1994;30:152-158.

4. Atherton D.J. The aetiology and management of irritant diaper dermatitis. J Eur Acad Dermatol Venereol. 2001;15(Suppl 1):1-4.

5. Atherton D.J.A review of the pathophysiology, prevention and treat-ment of irritant diaper dermatitis. Curr Med Res Opin. 2004;20:645-649.

6. Atherton D.J. Understanding irritant napkin dermatitis. Int J Dermatol. 2016;55(suppl 1):7-9.

7. Bender J.K., Faergemann J., Skold M. Skin health connected to the use of absorbent hygiene products: a review. Dermatol Ther (Heidelb). 2017;7:319-330.

8. Berg R.W., Buckingham K.W., Stewart R.L Etiologic factors in diaper dermatitis: the role of urine. Pediatr Dermatol. 1986;3:102-106.

9. Bewley A., Dermatology Working Group. Expert consensus: time for a change in the way we advise our patients to use topical corticosteroids. Br J Dermatol. 2008;158:917-920.

10. Blanco D., van Rossem K. A prospective twoyear assessment of miconazole resistance in Candida spp. with repeated treatment with $0.25 \%$ miconazole nitrate ointment in neonates and infants with moderate to severe diaper dermatitis complicated by cutaneous candidiasis. Pediatr Dermatol. 2013;30:717-724.

11. Blume-Peytavi U., Hauser M., Lunnemann L., et al. Prevention of dia-per dermatitis in infants-a literature review. Pediatr Dermatol. 2014;31:413-429.

12. Blume-Peytavi U., Lavender T., Jenerowicz D., et al. Recommendations from a European roundtable meeting on best practice healthy infant skin care. Pediatr Dermatol. 2016;33:311-321.

13. Blume-Peytavi U., Kanti V. Prevention and treatment of diaper dermatitis. Pediatric Dermatology. 2018;35:s19-s23.

14. Boiko S. Treatment of diaper dermatitis. Dermatologic Clinics. 1999;17(1):235-240.

15. Bonifaz A., Rojas R., Tirado-Sanchez A., et al. Superficial mycoses associated with diaper dermatitis. Mycopathologia. 2016;181:671-679.

16. Buckingham K.W., Berg R.W. Etiologic factors in diaper dermatitis: the role of feces. Pediatr Dermatol. 1986;3:107-112.

17. Brook I. Microbiology of secondarily infected diaper dermatitis. Int J Dermatol. 1992;31:700-702.

18. Brown W.M., Berg J.E., Li Q. et al. A clinical study to evaluate the efficacy of two marketed zinc oxide-based diaper rash ointments in children with diaper dermatitis. Clinical Dermatology Conference. Las Vegas, NV, 2006.

19. Coughlin C.C., Eichenfield L.F., Frieden IJ. Diaper dermatitis: clinical characteristics and differential diagnosis. Pediatr Dermatol. 2014;31(Suppl 1):19-24

20. Counts J., Weisbrod A., Yin S. Common Diaper Ingredient Questions: Modern Disposable Diaper Materials Are Safe and Extensively Tested. Clinical Pediatrics. 2017;56(5S):23S-27S

21. Dyer D. Seven decades of disposable diapers: a record of continuous innovation and expanding benefit. http://www. edana.org/docs/defaultsource/default-document-library/ seven-decadesof-disposable-diapers.pdf?sfvrsn=2.Published August 2005. Accessed February 8, 2017.

22. Ferrazzini G., Kaiser R.R., Hirsig Cheng S.K. et al. Microbiological aspects of diaper dermatitis. Dermatology. 2003;206:136-141.

23. Fölster-Holst R., Buchner M., Proksch E. Diaper dermatitis. Hautarzt. 2011;62:699-708.

24. Fölster-Holst R. Differential diagnoses of diaper dermatitis. Pediatr Dermatol. 2018 Mar;35(Suppl 1):s10-s18. doi: 10.1111/pde.13484.

25. Fluhr J.W., Darlenski R., Lachmann N., Baudouin C. Msika P., De Belilovsky C. \& Hachem J.P. Infant epidermal skin physiology: Adaptation aft er birth. British Journal of Dermatology. 2012;166(3): 483-490. doi:10.1111/j.1365-2133.2011.10659.x.

26. Jordan W.E., Lawson K.D., Berg R.W., et al. Diaper dermatitis: fre-quency and severity among a general infant population. Pediatr Dermatol. 1986;3:198-207.

27. Georgios N.S., Neena K.T. Diaper Dermatitis: Etiology, Manifestations, Prevention, and Management. Pediatric Dermatology. 2014;31(1):1-7.

28. Gupta A.K., Skinner A.R. Management of diaper dermatitis. Int J Dermatol. 2004;43:830-834.

29. Hoeger P.H., \& Enzmann C.C. Skin physiology of the neonate and young infant: A prospective study of functional skin parameters during early infancy. Pediatric Dermatology. 2002;19(3):256-262.

30. Humphrey S., Bergman J.N., Au S. Practical management strategies for diaper dermatitis. Skin Therapy Lett. 2006;11:1-6.

31. Kalia Y.N., Nonato L.B., Lund C.H. \& Guy R.H. Development of skin barrier function in premature infants. Journal of Investigative Dermatology. 1998;111(2):320-326. doi: 10.1046/j.1523-1747.1998.00289.x.

32. Klunk C., Domingues E., Wiss K. An update on diaper dermatitis. Clin Dermatol. 2014;32:477-487.

33. Kosemund K., Schlatter H., Ochsenhirt J., Krause E., Marsman D., Erasala G. Safety evaluation of superabsorbent baby diapers. Regul Toxicol Pharmacol. 2008;53:81-89.

34. Lavender T., Furber C., Campbell M., et al. Effect on skin hydration of using baby wipes to clean the napkin area of newborn babies: assessor- blinded randomised controlled equivalence trial. BMC Pediatr. 2012;12:59.

35. Liu N., Wang X., Odio M. Frequency and severity of diaper dermatitis with use of traditional Chinese cloth diapers: observations in 3- to 9-month-old children. Pediatr Dermatol. 2011;28:380-386.

36. Mancini AJ. Skin. Pediatrics. 2004;113:1114-1119.

37. Merrill L. Prevention, Treatment and Parent Education for Diaper Dermatitis. Nursing for Women's Health. 2015;19(Issue 4):326-337.

38. Nield L.S., Kamat D. Prevention, diagnosis, and management of diaper dermatitis. Clinical Pediatrics. 2007;46(6):480-486.

39. Nikolovski J., Stamatas G.N., Kollias N. \& Wiegand B.C. Barrier function and water-holding and transport properties of infant stratum corneum are diff erent from adult and continue to develop through the fi rst year of life. Journal of Investigative Dermatology. 2008;128(7):17281736. doi:10.1038/sj.jid.5701239.

40. Odio M.R., O'Connor R., Sarbaugh F., et al. Continuous topical administration of a petrolatum formulation by a novel disposable diaper. 2. Effect on skin condition. Dermatology. 2000;200:238-243.

41. Odio M., Thaman L. Diapering, diaper technology, and diaper area skin health. Pediatr Dermatol. 2014;31(suppl 1):9-14.

42. Odio M., Friedlander S.F. Diaper dermatitis and advances in diaper technology. Curr Opin Pediatr. 2000;12:342-346.

43. Odio M., O'Connor R., Sarbaugh F., Baldwin S. Continuous topical administration of a petrolatum formulation by a novel disposable diaper. 2. Effect on skin condition. Dermatology. 2000;200:238-243.

44. Sikic Pogacar M., Maver U., Marcun Varda N., et al. Diagnosis andmanagement of diaper dermatitis in infants with emphasis on skinmicrobiota in the diaper area. Int J Dermatol. 2017;57:265-275.

45. Schmidt N.A. Salivary cortisol testing in children. Issues Compr Pediatr Nurs. 1998;20:183-190.

46. Scheinfeld N. Diaper dermatitis: a review and brief survey of eruptions of the diaper area. Am J Clin Dermatol. 2005;6:273-281.

47. Stamatas G.N., Tierney N.K. Diaper dermatitis: etiology, manifestations, prevention, and management. Pediatr Dermatol. 2014;31:1-7.

48. van Gysel D., Kenneally D., Hatzopoulos I. Skin care and sustainability improvements with baby diaper developments. Eur Obstet Gynaecol Suppl. 2012;7(suppl 1):31-34.

49. Visscher M.O., Chatterjee R., Munson K.A. et al. Changes in diapered and nondiapered infant skin over the first month of life. Pediatr Dermatol. 2000;17:45-51.

50. Visscher M.O., Adam R., Brink S., Odio M. Newborn infant skin: physiology, development, and care. Clin Dermatol. 2015 May-Jun;33(3):271-80. doi: 10.1016/j.clindermatol.2014.12.003. 